\title{
(NON-HUMAN)ANIMAL COMPANIONSHIP: A CRUCIAL SUPPORT FOR PEOPLE DURING THE COVID-19 PANDEMIC
}

\author{
JANET HOY-GERLACH ${ }^{1}$, MARY RAUKTIS ${ }^{2} \&$ CHRISTINA NEWHILL $^{3}$ \\ ${ }^{1}$ The University of Toledo, 2801 W. Bancroft St. MS 119, Toledo Ohio 43606, USA. ORCID: 0000-0001- \\ 5578-9684, Email: Janet.hoy@utoledo.edu \\ ${ }^{2}$ The University of Pittsburgh, School of Social Work, 2117 Cathedral of Learning, 4200 Fifth Avenue, \\ Pittsburgh, PA 15260, USA. ORCID: 0000-0002-0161-9337, Email: Mar104@pitt.edu \\ ${ }^{3}$ The University of Pittsburgh, School of Social Work, 2117 Cathedral of Learning, 4200 Fifth Avenue, \\ Pittsburgh, PA 15260, USA. ORCID: 0000-0002-8536-0325, Email: newhill@pitt.edu
}

ABSTRACT: Background Human-animal interaction (HAI) offers benefits across physical, emotional, psychological, and social spheres of human functioning. The aim of this paper is to delineate how animal companionship, via provision of HAI benefits, offers vital support to people experiencing the COVID-19 pandemic and associated stressors. Method Each of the empirically supported types of HAI benefits - physical, emotional, psychological, and social - will be situated within a biopsychosocial framework of human functioning and considered in terms of how they may help to ameliorate stressors specifically related to the COVID-19 pandemic. Findings Benefits derived from animal companionship may help alleviate physical, emotional, psychological, and social stressors specifically related to experiencing the COVID-19 pandemic. Discussion Benefits of animal companionship may be particularly salient for well-being and coping when people are experiencing a dramatic increase in stressors via a pandemic crisis. Community responses need to include plans (pet food pantries, temporary foster care, veterinary access/zoonotic safety) for keeping people and their companion animals together during such difficult times. Originality/value This article 
is unique in that it delineates the animal companionship benefits in terms of how such may help alleviate stressors associated with a pandemic.

KEYWORDS: COVID-19, Coronavirus, quarantine, companion animal, pet

\section{INTRODUCTION}

The COVID-19 pandemic, in addition to being a physical health and economic crisis, has generated a pandemic-sized wave of related psychosocial stressors which some have referred to as the "Shadow Pandemic" (Wan et al. 2020). Human beings by nature are social mammals, hard-wired to connect and interact with each other (Correia-Caeiro, Katia and Mills 2020). Unfortunately, one of the most useful tools in reducing fatalities related to the COVID-19 virus entails what is broadly referred to as "social distancing"; this can be more accurately described as physically distancing from others outside of one's immediate household. U.S. guidelines at the time of writing this include: staying at least 6 feet from others; avoiding gatherings of ten or more people; and leaving home only for essential tasks such as caretaking, or obtaining food or medications (Pearce 2020). While the ability to connect widely via remote means remains for those who have access, people are nonetheless reporting feelings of increased loneliness, isolation, and stress (which has both physical and mental implications) (Stallard and Stallard 2020).

Animal companionship as a strategy to help reduce human loneliness and isolation had gained increased attention from a range of researchers, such as those focused on: isolation as a health risk factor via a social determinants of health framework (Mueller, Gee, and Bures 2018); aging and isolation (Friedman and Gee 2019); and those interested in general population well-being (Wells 2019; Chandler et al. 2015). An emerging body of empirical research has is being generated on the various benefits of having companion animals across human life stages; such research can be situated within biopsychosocial dimensions of human functioning as follows: physical benefits stemming from both direct contact with animals and increased activity related to animals; emotional benefits such as comfort and affection; psychological benefits such as motivation and feeling needed; and social benefits both directly related to the animal (e.g., companionship) and indirectly related to the animal (e.g., a bridge to connecting to others who enjoy animals) (Hoy-Gerlach, Vincent and Hector 2019; Hoy-Gerlach and Wehman 2017). These benefits are not experienced by people in a mutually exclusive way, rather, they occur within the integrated human experience across functional realms (Beetz et al. 2012).

The majority of households in the United States report having at least one companion animal, and the majority of those report that they consider their companion animal to be a family member (American Pet Products Association, 2019-2020). This is consistent with data from many other countries; a 2016 international study conducted by the Nuremburg-based international marketing think tank Growth from Knowledge (GfK) in 2016 concluded that over half of people internationally have at least one 
pet (Growth from Knowledge 2016). The benefits of animal companionship are thus already accessible for many households; given the current pandemic situation, easily accessible ways to ameliorate stress warrant immediate increased consideration. [There are also numerous stressors related to having an animal, such as behavioral, financial, and logistical concerns; all of these concerns may be amplified by the pandemic. To limit scope and focus of this paper, we are focusing on benefits, however, we will include resources and strategies for addressing stressors (as a way to maximize benefits) in the discussion section.]

The aim of this paper is to delineate how each of the types of benefits associated with animal companionship - physical, social, psychological, and emotional - may specifically be helpful in coping with pandemic-related stressors.

\section{PANDEMIC QUARANTINE-RELATED STRESSORS}

While there is a body of research on general stressors related to various pandemics, Brooks and colleagues in February 2020 published a synthetic literature review The psychological impact of quarantine and how to reduce it: rapid review of the evidence. This review is both rigorous and timely, and was written with a contextual focus on the emerging COVID-19 pandemic of 2020. Given such, we have chosen to situate the benefits of animal companionship within the stressors identified within this review. Brookes and colleagues (2020) define a quarantine as "the separation and restriction of movement of people who have potentially been exposed to a contagious disease to ascertain if they become unwell, so reducing the risk of them infecting others" (p. 912). Brooks and colleagues (2020) delineated stressors during quarantine as follows:

- Duration of quarantine - longer durations were associated with increased post-traumatic stress symptoms, avoidance behaviors, and anger.

- Fears of infection - including contracting infection and transmitting to others.

- Confinement - loss of usual routine, reduced social and physical contact, and subsequent boredom and frustration [emphasis added].

- Inadequate supplies - food, water, clothes, accommodation.

- Inadequate information - poor information from authorities about actions to take and purpose of quarantine.

- Financial - being unable to work and having to interrupt professional activities with no advanced planning (p. 916).

Animal companionship is by no means a panacea for addressing the above stressors; having a companion animal may worsen stress related to supplies such as pet food and vet care, and financial costs of such. There may also be increased stress related to lack of information about transmission risk. It is important to contextualize these stress risks; the majority of U.S. households who reported having companion animals also reported that they considered their animals as family members, and these same issues 
could present as stressors for other (human) family members. As related to pandemic-related confinement stressors, the empirically-supported benefits of animal companionship are highly salient, and can be leveraged and amplified. We must use every strategy at our disposal to address pandemic-related stressors, and benefits associated with animal companionship are widely available due to the high numbers of people who keep companion animals. Temporarily fostering shelter animals may also offer a viable way for people who are not ready or able to make a long-term commitment to experience the benefits of animal companionship during the pandemic.

\section{CROSS-WALKING ANIMAL COMPANIONSHIP BENEFITS WITH PANDEMIC CONFINEMENT STRESSORS}

\section{REDUCED PHYSICAL CONTACT IN CONFINEMENT AND PHYSICAL BENEFITS OF ANIMAL COMPANIONSHIP}

Pandemic-related confinement is associated with decreased physical contact and activity and increased anxiety; anxiety symptoms include physiological components such as increased heart rate, respiration rate, and blood pressure (American Psychiatric Association 2013). Physical benefits of animal companionship have the potential to help mitigate such physiological issues. The scientific evidence relating to the cardiovascular benefits of animal companionship is robust enough that the American Heart Association came out with a scientific statement summarizing such in 2013 (Levine et al. 2013); evidence has continued to accumulate since then (El-Qushayri et at. 2020; Krittanawong et al. 2020). Physical benefits from animal companionship can be divided into two categories: contact-related benefits and activity-related benefits (Levine et al. 2013).

Contact-related physical benefits of animal companionship are conveyed through holding, petting, cuddling, and even gazing at one's animal; when such happens with an animal one is bonded with, oxytocin is released (Beetz et al. 2012). Oxytocin is a bonding hormone that was first discovered in studies on breast feeding mothers and their infants; it was later determined that oxytocin was released between unrelated adults, and even across species (Beetz et al. 2012). Oxytocin release is associated with a generally pleasant feeling and a decrease in heart rate, respiration rate, and blood pressure, and has long been hypothesized to mediate the benefits of positive interactions between humans (Uvnäs-Moberg 1998); more recently oxytocin has also been hypothesized to mediate benefits of positive interactions between people and companion animals (Beetz et al. 2012). The physical responses of a human experiencing stress and/or anxiety include increased heart rate, respiration rate, and blood pressure (Clemente-Suárez and Ruisoto-Palomera 2020); contact with an animal one is positively affiliated with thus has the potential to directly mitigate such. People living through a pandemic who are quarantined or restricted in movement are susceptible to increased anxiety related to such (Brooks et al. 2020); seeking out one's companion animals during times of exacerbated anxiety has the potential to reduce distressing 
related physical symptoms. The mere act of touch may also be increasingly important during a pandemic for people who live alone or don't have other sources of physical contact/affection; companion animals can provide an invaluable source of touch and contact during a pandemic.

Having a companion animal - a dog in particular - may also be associated with increased physical activity (Potter and Satore-Baldwin 2019; Levine et al. 2013). Depending on the restrictiveness of the confinement order issued, people may still be permitted to walk their dogs. Engaging in play with companion animals indoors also offers a physical activity, albeit less rigorous. People are anecdotally reporting increases in dog walking (Hamilton City Council 2020); memes are even being widely generated showing dogs weary of walking due to dramatic increases in walks since quarantine. In addition to the physical health benefits associated with exercise, there are also protective mental health effects (Ashdown-Franks et al. 2020). In a meta-review of how exercise affects mental health; Ashdown-Franks and colleagues found that exercise reduced anxiety and depression in children, adults and older adults (Ashdown-Franks et al. 2020); walking a dog during confinement - provided safe physical distance from others is maintained - hence may be a way to help ameliorate confinement-related anxiety and depression.

\section{REDUCED SOCIAL CONTACT IN CONFINEMENT AND SOCIAL BENEFITS OF ANIMAL COMPANIONSHIP}

Perhaps at the heart of stress related to confinement and quarantine during pandemics such as COVID-19 relates to the separation from others that must occur - e.g. physical distancing - as a public health tool to reduce spread. The companionship of non-human animals is not a substitution for human companionship (Vivers 2014); however, it is a unique companionship venue and with host of related benefits. People who live with companion animal report what is referred to as direct social benefits, e.g. the social benefits that directly relate to the animal's presence and company. People who lived alone, in a recent study of Emotional Support Animals, reported that "I still have a furry somebody to be with at home" and "I'm not alone, I have him [the dog]" (Hoy-Gerlach 2019). Within this study, people experienced statistically significant reductions in loneliness on the UCLA Loneliness Scale after residing with their animals, and the reduction in loneliness was strongly corroborated in qualitative data as associated to the presence of the respective animals (Hoy-Gerlach 2019).

The indirect social benefits of animal companionship, e.g., the ability of animals to connect us to like-minded humans who enjoy animals, also holds up if considered in the context of a pandemic. While people are much less likely to interact with other people in-person about animals during a pandemic, through remote and online contexts, the bridge to others continues to extend through posts and pictures about one's animals, which invites commentary from others. This may serve as both a distraction and a way to engage with others that is not pandemic-specific in focus. Such may help to address boredom and frustration experienced by individuals who are confining themselves during a pandemic (Brookes et al. 2020). 
Social support is often depicted along two dimensions: instrumental and emotional (Otsuka et al. 2019). Instrumental social support includes the provision of assistance related to tasks and information; concrete and specific help; in contrast, emotional social support is understood to be more subjectively experienced and related to comfort, affection, and other subjectively experienced emotional states (Otsuka et al. 2019). It is thus reasonable to extend the social stress associated with confinement to encompass a reduction in accessing emotional support. The presence of and interaction with companion animals can fill a crucial void during such times. Companion animals have active agency and both initiate and respond to initiations with people, related to petting, playing, and otherwise positively interacting and/or expressing affection (Vitztum and Urbanik 2016). In a study on individuals with cancer and their companion animals, participants reported their companion animals as primary sources of emotional support (Nitkin and Buchanan 2020); individuals with Emotional Support Animals likewise reported that their animals were a crucial provider of emotional support via affection and comfort (Hoy-Gerlach 2019).

\section{PSYCHOLOGICAL BENEFITS OF ANIMAL COMPANIONSHIP DURING CONFINEMENT}

Psychological benefits of human-animal interaction include but are not limited to: a sense of purpose; self-efficacy; behavior activation/motivation; and having routine/ structure (Brooks et al. 2018). In considering the loss of routine experienced during pandemic confinement, as noted by Brookes and colleagues (2020), living with a companion animal may offer some continuance of typical daily activities and routines. Companion animals are typically creatures of habit; they quickly learn and anticipate routines, and respond in various ways when such routines are not maintained. Companion animals may thus serve to prompt their humans to maintain daily routines related to walking, feeding, interacting, and so forth, even within a confinement situation. In the recent study on people with ESAs, the majority of participants did not work, and described how having a companion animal resulted in them following a more prescriptive routine each day: "I had to get up, I had to feed her and take her out in the morning, I couldn't lay in bed all day" (Hoy-Gerlach 2019).

The commitment to maintaining such roles for companion animals is likely associated with another psychological benefit; feeling a care-taking role/needed with regards to the companion animal. Several studies have identified this as a benefit in having a companion animal (Brooks et al. 2018). Again, in looking at the recent ESA study, participants illustrate such: "she can't do for herself, if it was just me I'd lay in bed all day, but she needs me to get up and take care of her at a decent time"; and "I have someone who needs me, I just can't lay around" (Hoy-Gerlach 2019).

Other psychological benefits related to animal companionship that likely undergird maintenance of structure and routine include self-efficacy and motivation/activation (Hoy-Gerlach 2019; Rauktis 2019). Self-efficacy pertains to feeling competent in being able to care for one's animal; while many other things may be uncertain, one's animal's health and well-being may be clearly maintained through taking good care of 
the animal. Having a companion animal has been associated with motivating self-care behavior associated with obtaining healthy food (Rauktis 2019) and general self-care (Hoy-Gerlach 2019); both of these studies indicated that participants explicitly linked their increased self-care behavior with their animals' dependence upon them. With regard to obtaining food, a study on food-security among individuals found that people with companion animals were actually more food-secure - a surprising finding as there are many anecdotes of people sharing their food with pets and thus having less food resources - due to proactively seeking food resources for their animals.

\section{DISCUSSION AND CONCLUSION}

In sum, our animals may motivate us to take better care of ourselves in a quarantine/ confinement situation, because we know they are dependent upon us. In addition, they are likely to provide an invaluable resource of comfort, physical contact, activity motivation, and connection to others. With regards to public health considerations to such, supports for benefits related to animal companionship - including mitigation of associated stressors - should be built in to system-wide infrastructure and responses.

It's already widely known that people tend not to leave animal family members behind, be it in personal crises such as intimate partner violence (McGraw and Jeffers 2015), or mass disasters such as Hurricane Katrina (Glassey 2018). It's reasonable to extrapolate that people will likewise include their animal family members in their responses to a mass disaster such as a pandemic. Hence, addressing companion animal stressors related to finances and resources may be especially helpful during a pandemic. Examples of supports that address resources include: pet food banks; pet food bank delivery service; temporary foster care in the event of illness or inability to care due to workload (e.g. healthcare providers); and other pet care supports such as free dog walking for those in healthcare positions who are working double shifts.

Examples of supports that explicitly address cost concerns include accessible, affordable veterinary care, which is an ongoing problem in general societal times, and is likely to be exacerbated due to COVID-19 concerns. The University of Tennessee in the United States (Larkin 2018), the Humane Society of the United States (Humane Society of the United States 2020) and the American Society of Prevention of Cruelty to Animals (American Society for the Prevention of Cruelty to Animals 2020) have each launched national initiatives in the United States to support people in keeping their companion animals; the partnership of human healthcare and service organizations will be invaluable in the success of such efforts. It is through a One Health/One Welfare approach (Menna et al. 2019) that efforts of human welfare and animal welfare organization efforts can be maximized for the best possible outcomes, for people and animals.

Simply put, One Health refers to the interconnectedness between human, (non-human) animal, and planetary well-being (Menna et al. 2019). What is good for one is generally good for the others; it is through working across disciplines and sectors that solutions and supports for well-being will be found for the COVID-19. The relationships of people with their companion animals are a pre-existing condition and poten- 
tially invaluable support for well-being, especially during this time of confinement to mitigate COVID-19 risk. Understanding and supporting these benefits, as well as proactively working to mitigate stressors related to having a companion animal, are crucial strategies to promoting well-being during this pandemic.

FUNDING: This research received no external funding.

CONFLICT OF INTEREST: The authors declare no conflict of interest.

\section{REFERENCES}

American Pet Products Association. 2019-2020. “APPA National Pet Owners Survey Statistics.” Retrieved March 30, 2020 (https://www.americanpetproducts.org/ press industrytrends.asp).

American Psychiatric Association. 2013. Diagnostic and statistical manual of mental disorders: DSM-5. Arlington, VA: American Psychiatric Association.

American Society for the Prevention of Cruelty to Animals. "What are Pet Safety Net

Services?”. 2020. Retrieved March 30, 2020 (https://www.aspca.org/animal-protection/safety-net ).

Ashdown-Franks, Garcia, Joseph Firth, Rebekah Carney, Andre F. Carvalho, Mats Hallgren, Ai Koyanagi, Simon Rosenbaum et al. 2020. "Exercise as Medicine for Mental and Substance Use Disorders: A Meta-Review of the Benefits for Neuropsychiatric and Cognitive Outcomes." Sports Medicine 50(1): 151-70. http://search.ebscohost.com/login.aspx?direct=true \&AuthType $=$ shib \& db=eoah\&AN $=51512515$ \&site $=$ ehost-live.

Beetz, Andrea, Kerstin Uvnäs-Moberg, Henri Julius, and Kurt Kotrschal. 2012. "Psychosocial and Psychophysiological Effects of Human-Animal Interactions: The Possible Role of Oxytocin.” Frontiers in Psychology 3 (July). http:// search.ebscohost.com/login.aspx?direct=true \&AuthType=shib \&db=psyh\&AN=2012-26242-001 \&site=ehost-live.

Brooks, Helen Louise, Kelly Rushton, Karina Lovell, Penny Bee, Lauren Walker, Laura Grant, and Anne Rogers. 2018. "The Power of Support from Companion Animals for People Living with Mental Health Problems: A Systematic Review and Narrative Synthesis of the Evidence.” BMC Psychiatry 18(1): 31. DOI: 10.1186/s12888018-1613-2.

Brooks, Samantha K., Rebecca K. Webster, Louise E. Smith, Lisa Woodland, Simon Wessely, Neil Greenberg, and Gideon James Rubin. 2020. “The Psychological Impact of Quarantine and How to Reduce It: Rapid Review of the Evidence.” Lancet 395 (10227): 912-20. doi:10.1016/S0140-6736(20)30460-8.

Chandler, Cynthia K., Delini M. Fernando, Casey A. Barrio Minton, and Torey L. Portrie-Bethke. 2015. "Eight Domains of Pet-Owner Wellness: Valuing the Own- 
er-Pet Relationship in the Counseling Process." Journal of Mental Health Counseling 37(3) (July 2015): 268-82. doi:10.17744/mehc.37.3.06.

Clemente-Suárez, Vicente Javier, and Pablo Ruisoto-Palomera. 2020. "Effects of the Psychophysiological Stress Response in Human Behavior.” Physiology \& Behavior 214 (February): 112761. doi:10.1016/j.physbeh.2019.112761.

Correia-Caeiro, Catia, Kun Guo, and Daniel S. Mills. 2020. "Perception of Dynamic Facial Expressions of Emotion between Dogs and Humans.” Animal Cognition, February 12, 2020. doi:10.1007/s10071-020-01348-5.

El-Qushayri, A. E., Kamel, A. M. A., Faraj, H. A., Vuong, N. L., Diab, O. M., Istanbuly, S., Elshafei, T. A., Makram, O. M., Sattar, Z., Istanbuly, O., Mukit, S. A. A., Elfaituri, M. K., Low, S. K., \& Huy, N. T. 2020. "Association between pet ownership and cardiovascular risks and mortality: a systematic review and meta-analysis." Journal of Cardiovascular Medicine (Hagerstown, Md.). https://doi.org/10.2459/ JCM.0000000000000920

Friedmann, Erika, and Nancy R Gee. 2019. "Critical Review of Research Methods Used to Consider the Impact of Human-Animal Interaction on Older Adults' Health.” Gerontologist 59(5): 964-72. doi:10.1093/geront/gnx150.

Glassey, Steve. 2018. "Did Harvey Learn from Katrina? Initial Observations of the Response to Companion Animals during Hurricane Harvey." Animals (2076-2615) 8(4): 47. doi:10.3390/ani8040047.

Growth from Knowledge (GfK). 2016. "Pet owners Dominate in Latin America, Russia, and the United States.” May 24, 2016. Retrieved March 30, 2020 (https:// www.gfk.com/fileadmin/user upload/website content/Global_Study/Documents/20160524_PM Pet_ownership_efin.pdf ).

Hamilton City Council. 2020. “Keep Dogs on Lead”. April 2, 2020. Retrieved March 30, 2020 (https://www.scoop.co.nz/stories/AK2004/S00049/keep-dogs-on-a-leadhelp-prevent-the-spread-of-covid-19.htm ).

Hendrik. 2014. "The Psychology of Animal Companionship: Some Ancient and Modern Views." Hervormde Teologiese Studies 70(1): 1-8. doi:10.4102/hts.v70i1.2705. Hoy-Gerlach, J. 2019. “The Hope and Recovery Pet (HARP) Program Evaluation: A Final Report to the Kenneth A. Scott Charitable Trust”. Prepared by Janet Hoy-Gerlach, LISW, PhD Associate Professor of Social Work, University of Toledo December 31, 2019. Unpublished manuscript.

Hoy-Gerlach, Janet, Aviva Vincent, and Becca Lory Hector. 2019. "Emotional Support Animals in the United States: Emergent Guidelines for Mental Health Clinicians." Journal of Psychosocial Rehabilitation and Mental Health 6(2): 199-208. http://search.ebscohost.com/login.aspx?direct=true \&AuthType $=$ shib \& db=eoah \&AN $=50841568 \&$ site $=$ ehost-live.

Hoy-Gerlach, Janet, and Scott Wehman. 2017. Human-Animal Interactions: A Social Work Guide. Washington DC: NASW Press.

Humane Society of the United States. 2020. "Keeping Pets for Life.” 2020. Retrieved March 30, 2020 (https://www.humanesociety.org/issues/keeping-pets-life ).

Krittanawong, C., Kumar, A., Wang, Z., Jneid, H., Virani, S. S., \& Levine, G. N. 2020. "Pet Ownership and Cardiovascular Health in the US General Population." The 
American Journal of Cardiology 125(8): 1158-1161.

Larkin, Malinda. 2018. “\$2.8M Grant to Aid Access to Veterinary Care: Maddie’s Fund to Support Research and Development of AlignCare." Journal of the American Veterinary Medical Association 253(6): 666-67. http://search.ebscohost.com/login.aspx?direct=true \&AuthType $=$ shib \&db=bai \&AN=131760427 \&site=ehost-live.

Levine, Glenn N., Karen Allen, Lynne T. Braun, Hayley E. Christian, Erika Friedmann, Kathryn A. Taubert, Sue Ann Thomas, Deborah L. Wells, and Richard A. Lange. 2013. "Pet Ownership and Cardiovascular Risk: A Scientific Statement from the American Heart Association.” Circulation 127(23): 2353-63. doi:10.1161/ CIR.0b013e31829201e1.

McGraw, C. \& S. Jeffers. 2015. “The importance of considering the treatment and care of family pets in domestic violence risk assessments." Journal of Health Visiting 3(9): 483-488.

Menna, Lucia Francesca, Antonio Santaniello, Margherita Todisco, Alessia Amato, Luca Borrelli, Cristiano Scandurra, and Alessandro Fioretti. 2019. "The Human-Animal Relationship as the Focus of Animal-Assisted Interventions: A One Health Approach.” International Journal of Environmental Research and Public Health 16(19). doi:10.3390/ijerph16193660.

Mueller, Megan K., Nancy R. Gee, and Regina M. Bures. 2018. “Human-Animal Interaction as a Social Determinant of Health: Descriptive Findings from the Health and Retirement Study.” BMC Public Health 18(1): 305. doi:10.1186/s12889-0185188-0.

Nitkin, Patricia and Marla J. Buchanan. 2020. "Relationships Between People with Cancer and Their Companion Animals: What Helps and Hinders.” Anthrozoös 33(2): 243-59. http://search.ebscohost.com/login.aspx?direct=true \&AuthType $=$ shib \&db=eoah \&AN=52709750\&site=ehost-live.

Otsuka, Tatsui, Yasutake Tomata, Shu Zhang, Fumiya Tanji, Yumi Sugawara, and Ichiro Tsuji. 2019. "The Association between Emotional and Instrumental Social Support and Risk of Suicide Death: A Population-Based Cohort Study.” Journal of Psychiatric Research 114(July): 141-46. doi:10.1016/j.jpsychires.2019.04.012.

Pearce, Katie. 2020. "What is Social Distancing and How Can it Slow the Spread of COVID-19.” March 13, 2020. John Hopkins University COVID-19 Online Hub. Retrieved March 30, 2020 (https://hub.jhu.edu/2020/03/13/what-is-social-distancing $/$ ).

Potter, Katie and Melanie Sartore-Baldwin. 2019. “Dogs as Support and Motivation for Physical Activity.” Current Sports Medicine Reports 18(7): 275-80. doi:10.1249/ JSR.0000000000000611.

Rauktis, M. E. 2019. “The Impact of Pets on Food Security.” Manuscript in Revision at Anthrozoos March 2020.

Stallard, Michael Lee and Katharine P. Stallard. 2020. “COVID-19 Is Coinciding With a Loneliness Epidemic.” Government Executive, March, N.PAG. http://search. ebscohost.com/login.aspx?direct=true \&AuthType $=$ shib \& db=0ih \&AN=1424Uvnäs-Moberg, Kerstin. 1998. "Oxytocin May Mediate the Benefits of Positive Social Interaction and Emotions.” Psychoneuroendocrinology, Is there a neurobiology 
of love?, 23 (8): 819-35. doi:10.1016/S0306-4530(98)00056-0.38635\&site=ehost-live.

Uvnäs-Moberg, Kerstin. 1998. “Oxytocin May Mediate the Benefits of Positive Social Interaction and Emotions." Psychoneuroendocrinology 23(8): 819-35. doi:10.1016/ S0306-4530(98)00056-0.

Vitztum, Coley and Julie Urbanik. 2016. "Assessing the Dog: A Theoretical Analysis of the Companion Animal's Actions in Human-Animal Interactions." Society \& Animals 24(2): 172-85. doi:10.1163/15685306-12341399.

Viviers, Hendrik. 2014. "The Psychology of Animal Companionship: Some Ancient and Modern Views." Hervormde Teologiese Studies 70(1): 1-8. doi:10.4102/hts. v70i1.2705.

Wan, William, Joel Achenbach, Carolyn Y. Johnson, and Ben Guarinao. 2020. "Report: Radical Restrictions for 12-18 Months could be 'the only viable strategy'." March 19, 2020 The Washington Post. Retrieved March 30, 2020 (https://www.boston. com/news/health/2020/03/19/report-radical-restrictions-for-12-18-monthscould-be-the-only-viable-strategy ).

Wells, Deborah L. 2019. “The State of Research on Human-Animal Relations: Implications for Human Health.” Anthrozoos 32(2): 169-81. doi:10.1080/08927936.2019 .1569902 .

\section{BIOGRAPHICAL NOTE}

Janet Hoy-Gerlach is associate professor of social work at the University of Toledo, USA.

Mary Rauktis is assistant research faculty at School of Social Work, The University of Pittsburgh, USA.

Christina Newhill is professor at School of Social Work, The University of Pittsburgh, USA.

OPEN ACCESS: This article is distributed under the terms of the Creative Commons Attribution Non-commercial License (CC BY-NC 4.0) which permits any non-commercial use, and reproduction in any medium, provided the original author(s) and source are credited.

ARTICLE HISTORY: Received 2020-03-30 / Accepted 2020-04-06 
